\title{
Effect of Superabsorbent Polymer as Partial Replacement of Portland Cement on Electrochemical Corrosion Behavior of Carbon Steel Rebar in Artificial Seawater
}

\author{
Baoqing Zhang ${ }^{1,2}$ \\ ${ }^{1}$ School of Water \& Architectural Engineering, Shihezi University, Shihezi 832000, China \\ ${ }^{2}$ School of Architecture and Urban planning, Huazhong University of Science and Tecnology, \\ Wuhan Hubei 430047 China \\ E-mail: baoqingzhang86@ sina.com and D201677799@hust.edu.cn
}

doi: $10.20964 / 2021.04 .51$

Received: 31 December 2020 / Accepted: 2 February 2021 / Published: 28 February 2021

\begin{abstract}
The effect of superabsorbent polymer (SAP) powder and fly ash (FA) content into concrete structures on the corrosion behavior of carbon steel rebar was studied. SAPs were applied at various volume fractions $(0.1 \%, 0.2 \%$, and $0.4 \%)$. All the SAP-modified concrete samples contained $15 \mathrm{wt} \%$ FA as a cement replacement. The electrochemical analysis was done by electrochemical impedance spectroscopy (EIS) and polarization measurement assessments in $3.5 \mathrm{wt} \% \mathrm{NaCl}$ as artificial seawater. The EIS results fitted by an appropriate equivalent electrical circuit indicated that the highest corrosion resistance was achieved for the SAP4 mixture. Polarization analysis revealed that the SAP4 sample has the lowest corrosion current density, more positive corrosion potential with high corrosion protection. These electrochemical results show that the simultaneous addition of FA and SAPs admixtures in concrete structures improve the concrete durability and corrosion resistance of carbon steel rebar after being exposed to an aggressive environment by preventing the rebar surface from reaching the corrosive ions.
\end{abstract}

Keywords: Superabsorbent polymer powder; Fly ash admixture; Carbon steel reinforced concrete;Electrochemical corrosion behavior

\section{$\underline{\text { FULL TEXT }}$}

(C) 2021 The Authors. Published by ESG (www.electrochemsci.org). This article is an open access article distributed under the terms and conditions of the Creative Commons Attribution license (http://creativecommons.org/licenses/by/4.0/). 